\title{
Patent Medicine Sellers: How Can They Help Control Childhood Malaria?
}

\author{
Rosamund M. Akuse, ${ }^{1}$ Edwin E. Eseigbe, ${ }^{1}$ Abubakar Ahmed, ${ }^{2}$ and William R. Brieger ${ }^{3}$ \\ ${ }^{1}$ Department of Paediatrics, Ahmadu Bello University Teaching Hospital, Zaria 810006, Nigeria \\ ${ }^{2}$ Research and Statistics Unit, National Eye Centre, Kaduna PMB 2267, Nigeria \\ ${ }^{3}$ Department of International Health, Bloomberg School of Public Health, Johns Hopkins University, Baltimore MD 21205, USA
}

Correspondence should be addressed to Rosamund M. Akuse, ros2akuse@yahoo.co.uk

Received 18 May 2010; Accepted 19 July 2010

Academic Editor: Giampietro Corradin

Copyright ( $\odot 2010$ Rosamund M. Akuse et al. This is an open access article distributed under the Creative Commons Attribution License, which permits unrestricted use, distribution, and reproduction in any medium, provided the original work is properly cited.

Roll Back Malaria Initiative encourages participation of private health providers in malaria control because mothers seek care for sick children from them. This study investigated Patent Medicine Sellers (PMS) management of presumptive malaria in children in order to identify how they can assist malaria control. A cross-sectional survey of 491 PMS in Kaduna, Nigeria, was done using interviews and observation of shop activities. Most (80\%) customers bought drugs without prescriptions. Only 29.5\% were given instructions about doses. Between 40-100\% doses of recommended antimalarials were incorrect. Some (22\%) PMS did not ask questions about illness for which they were consulted. Most children treated in shops received injections. PMS facilitate homecare but have deficiencies in knowledge and practice. Interventions must focus on training them to accurately determine doses, give advice about drug administration, use oral medication, and ask about illness. Training should be made a prerequisite for registering and reregistering shops.

\section{Introduction}

If Africa is to achieve the Millennium Development Goal (MDG) of reducing childhood mortality by two thirds by 2015, new approaches to healthcare delivery must be developed [1]. Despite various national and international efforts, malaria still remains a major cause of childhood mortality accounting for about 800,000 deaths annually [2, $3]$. As over $80 \%$ of these deaths occur in African children under the age of five, it will be difficult to achieve the MDG goals without substantially reducing the burden of malaria [3]. The Roll Back Malaria (RBM) Partnership was established to coordinate a global approach to combat malaria, and at an RBM meeting in 2000, African heads of the state pledged to ensure that $60 \%$ of people suffering from malaria have access to affordable and appropriate treatment within 24 hours of the onset of illness and $60 \%$ of children and pregnant women sleep under Insecticide-treated Nets [3]. Treatment starting within 24 hours of the onset of symptoms prevents progression to severe malaria or death
[4]. However strategies to achieve this goal must take into account populations that do not patronize public health facilities or are inadequately served by them. Often children do not reach public facilities untill three or more days after the onset of symptoms because they are treated at home or by private health providers in the community [5-9]. Yet until recently private health providers were not the focus of intervention programs but now the Roll Back Malaria Initiative is encouraging participation of all private Health Providers within overall government strategies for malaria control [9].

Patent medicine sellers (PMS) are a large group of informal private health providers found in many countries who operate as shop keepers, traders in periodic markets, itinerant drug peddlers, and wholesale drug merchants [10, 11]. Those who operate from shops are patronized by people from all segments of the community especially the poor because they are perceived to be more accessible, caring, and affordable than public health facilities [7, 8, 10-12]. They are a source of drugs, advice, and treatment for illnesses in 
many communities [10-16]. They have no formal pharmacy training but are licensed to sell proprietary and over-thecounter drugs [16]. However many of their practices have been reported to be substandard $[10,14,15]$. Policy makers have generally ignored them, attempted to redirect customers away from them, or tried (usually unsuccessfully) to enforce regulations preventing them from acting as health providers $[10,17]$. Few reported interventions have tried to work with them to improve management of malaria, and there is little or no exchange of information or collaboration between government bodies and PMS. The result is that there is a huge, largely unregulated resource which is not being utilized to contribute to national child survival initiatives $[10,17]$. But because $15 \%-82 \%$ of caregivers in sub-Saharan Africa first consult them for treatment of their sick children, it is increasingly being recognized that they must be included in malaria control programmes [10, 17].

Various strategies like information, incentives, persuasion, social marketing, franchise, or accreditation have been suggested to improve their practices $[10,17,18]$. These all need research into which method or combination of methods is the best, but whichever method is used, PMS would need to acquire some basic knowledge and probably training. In order to determine how best PMS can be used in malaria control in children, it is important to determine exactly what they do for sick children. Such information however has been based mainly on interviews, use of mystery clients and anecdotes [19-22]. Few studies have documented what actually happens when caregivers visit PMS shops [23]. Partly because of the attitude of some health professionals and partly for fear of legal repercussions, PMS are often reluctant to divulge information about their activities. Even where they do, there is sometimes a discrepancy between what they say they do and what they actually do [22]. Ideally, studies about PMS should involve a combination of methods, for example, direct observations of their activities and interviews to allow for validation and increase of the relevance and generalization of results [24]. For this reason a combination of methods was used in this study whose aim was to investigate how PMS manage presumptive malaria in children under 5 years in Kaduna, Nigeria, specifically to determine the characteristics of PMS and the services they offer, and for those who manage children, to document how they identify and treat presumptive malaria. It is hoped that the findings would provide program managers and policy makers substantial grounds to integrate PMS into malaria control programs and assist in the development of interventions for them. This would help reduce childhood mortality in Nigeria and other countries where PMS operate.

\section{Subjects and Methods}

2.1. Background of Study Area. Nigeria, the most populous country in Africa, has one of the highest childhood mortality rates in the world with malaria accounting for 30\% of mortality [25, 26]. Kaduna city is the capital of Kaduna State. It was the capital of the former Northern region and is an important city in the North of Nigeria. It is situated in the Northwestern health zone which has the highest Under-Five
Mortality Rate of the six health zones in the country [27]. In the early 1900s, various parts of the country were linked to Kaduna by rail. This led to people of different ethnic groups migrating to Kaduna. People from the major ethnic groups (Hausa, Yoruba, and Ibo) and numerous minor ethnic groups have settled in Kaduna. The main local language spoken by most residents is Hausa, but a lot of people are multilingual. The residents of Kaduna practice Christianity, Islam, and traditional religions. Sometimes ethnic and religious tensions erupt into riots (the last occurred in 2000). Many people work in the textile, car assembly, and oil refining industries, the civil service, and the small-scale businesses [28]. The city is made up of 2 administrative areas: Kaduna North and South Local Government Areas (LGAs). Each LGA is a mixture of high-, medium-, and low-density areas supporting various commercial and industrial activities with people of different sociocultural, ethnic, and religious backgrounds. The city had an estimated population of a million at the time of the study.

Knowledge about PMS management of sick children in Kaduna is scanty as most studies about PMS were carried out in Southern Nigeria where the population, culture, and perceptions differ from those of the North. Studies from the South were carried out in urban and rural areas but involved populations which were homogenous in ethnicity and religion [7, 20, 29]. In contrast, Kaduna is an urban area with a heterogeneous population in terms of religion, ethnicity and culture [28]. Though there are no published data, it appears that the proportion of people patronizing PMS in Kaduna is increasing in spite of the presence of many orthodox health facilities including a University Teaching Hospital, a paediatric hospital, 3 general hospitals, 10 primary healthcare centres, and 93 registered fee-paying private hospitals.

PMS are expected to be over 21 years of age with at least primary school education before they can be registered by the State Ministry of Health (SMOH) [16]. Registered PMS are issued licenses which they are supposed to renew every year and display in their shops. The Task Force of the $\mathrm{SMOH}$ carries out periodic inspections to make sure that PMS comply with regulations. Kaduna city had 220 registered PMS shops. There are also an unknown number of PMS who, because they are not registered by the $\mathrm{SMOH}$, are not supposed to sell drugs but who nevertheless do so. Both registered and unregistered PMS belong to the National Association of Patent and Proprietary Medicine Dealers (NAPPMED), membership of which is voluntary.

2.2. Study Design. The study carried out in 2003 was a cross-sectional, descriptive survey of all PMS in Kaduna South LGA. Only PMS operating in shops (registered and unregistered) were studied because these appear to be the ones most patronized by caregivers of sick children $[10,11$, 17]. Traders in periodic markets, itinerant drug peddlers, and wholesale drug merchants were excluded. PMS shops were identified by research assistants who combed the area. Two research instruments were used-a questionnaire used to interview PMS and a detailed checklist used during direct observation of customer-PMS interactions. A pretest was 
carried out in an area similar to but far away from the study area to validate both instruments.

The questionnaire was translated from English to Hausa (the commonest local language in the study area) and backtranslated into English by an independent translator to ensure correct translation. The translation was done so that it could be used for PMS who were not fluent in English. The questionnaire contained questions about the characteristics of PMS, the shop, the services they offered both adults and children, and the methods they used to identify and manage or refer children with presumptive malaria. An inventory of drugs sold for malaria in the week preceding the interview was taken. Questions were also asked about the type, the methods of administration, and the doses of medicines (if any) given to treat children they thought had malaria. The questionnaire was administered by trained research assistants, and interviews were carried out with the PMS who attended to customers.

The detailed checklist was used to record the number, sex, estimated ages, and actions of all visits by customers whether these visits were of a medical nature; it also recorded the response of PMS (including whether the customer was asked questions about illness, sale of drugs, giving of advice, physical examination, and any treatment given). During the visits, trained research assistants recorded activities in shops and observations were made of customer-PMS interactions. This was done at different times of the day for one hour using the detailed checklist. A maximum of 20 observations per shop were recorded in the one-hour period. Data recorded were based on consecutive arrival of clients at shops. In order to minimize interference with customer-PMS interactions, the research assistants did not interfere with shop activities or ask customers any questions and no exit interviews of customers were done.

2.3. Sample Size Estimation. Studies which conducted observations of customer-health worker interactions at government health facilities recorded different numbers of observations ranging from two observations per condition [30] to six observations per facility [31]. None of these studies provided a rationale for the number of observations made or the time spent. Shop observations studies from Southern Nigeria indicated that 10 observations per shop were adequate to obtain significant information and avoid the cluster effect of the same individual repeating his behaviour [23]. Further the study pretest indicated that approximately $50 \%$ of customers' visits were for nonmedical purposes and about $20 \%$ of sales concern children less than 5 years.

Kaduna city had 220 registered PMS shops. Thus the number of total observations needed for the shops was calculated as $220 \times 10=2200$. INSTAT V2.02 (Graphpad software1990-1993) was used to calculate the sample size. A $5 \%$ level of precision was used taking into account the resources available for the study.

At expected sales for children of $20 \%( \pm 5 \%)$, with $\alpha=$ 0.05 and $\beta=0.20$, the minimum number of visits by customers that would give an adequate number of customerPMS observations was calculated to be 471 . The visits that represent under- 5 children equal $2200 \div 471=4.6 \cong 5$.
Thus the number of visits that will represent total children visits equals $5 \times 220=1100$. With an estimated 10 customerPMS observations per shop, the total number of shops to be studied equals $1100 \div 10=110$. Since this represented the approximate number of shops in one LGA of the city, all the PMS in the LGA were to be surveyed. As approximately $50 \%$ of customers' visits were for non-medical purposes, the number of observations was increased to 20 . This was the maximum number of customer-PMS observations recorded in the one-hour period the by the trained researcher.

\subsection{Ethical Approval, Consent, and Confidentiality. Approval} was obtained from the Scientific and Ethical Committee of Ahmadu Bello University Teaching Hospital, Zaria, Nigeria and the Institutional Review Board of Boston University, North America. Informed consent was obtained from the State Chairman of the National Association of Patent and Propriety Medicine Dealers (NAPPMED), each local head of NAPPMED, the owner of each shop, and individuals enrolled in the survey. Confidentiality was ensured and no person or shop was identified by name.

2.5. Data Management. Variables analyzed included characteristics of the PMS, the shop, customers, and child for whom help was sought. Drugs PMS recommended for malaria were classified into pharmacological groups and doses were classified as correct, underdose, or overdose in accordance with national treatment guidelines, for example, chloroquine dose was deemed appropriate when given orally in a dose of $25 \mathrm{mg} / \mathrm{kg}$ base over 3 days [32]. Possible factors that could influence the behaviour of different groups of PMS (e.g., gender, age, educational background, and location of shop) were compared in terms of proportions and tests of significance using chi-squared tested and Student $t$-test to detect statistically significant differences $(P<.05)$. Statistical analysis was done with EPIINFO version 6.04. PMS with missing information were excluded when calculating significance levels.

\section{Results}

3.1. Characteristics of Shops. All PMS shops in the Kaduna South LGA were to be included in the study. The expected number of shops was 110 , but on the field, a total of 544 shops were identified. However 53 (9.7\%) owners were unavailable or refused to participate in the study mainly because of suspicion that researchers were members of the State Monitoring Task Force. Most 440 (89.6\%) of the remaining 491 shops claimed to be registered but only $56 \%$ displayed licenses. The majority $(87.8 \%)$ of shops was situated near busy places (main roads or markets), $8.1 \%$ near health facilities, and the rest near hotels, places of worship, or residential areas. Most of them (94.7\%) were open 6 or 7 days a week from early morning untill late at night, and $48.3 \%$ also sold general store items. Services available for children less than 5 included giving medical advice (97.8\%), consultation for illness (94.7\%), administration of injections (40.7\%), and intravenous fluids (18.5\%). Some shops (37\%) 
TABLE 1: Characteristics of patent medicine sellers.

\begin{tabular}{lc}
\hline Sex & Number $(\%)$ \\
\hline Male & $328(66.8 \%)$ \\
Female & $163(33.2 \%)$ \\
\hline Age (years) & $34(6.9 \%)$ \\
\hline$<21$ & $374(76.2 \%)$ \\
$21-40$ & $73(14.9 \%)$ \\
$>41$ & \\
\hline Highest education attained & $44(8.96 \%)$ \\
\hline Primary & $255(51.9 \%)$ \\
Secondary & $192(39.1 \%)$ \\
Tertiary & $374(76.2 \%)$ \\
\hline Training in orthodox healthcare & $117(23.8 \%)$ \\
\hline None & 2 \\
Healthcare training & 97 \\
$\quad$ Dentists & 18 \\
\hline Nurses/Midwives &
\end{tabular}

had the services of a medical doctor or nurse (mostly on a part-time basis) to see patients.

3.2. Characteristics of PMS (Table 1). PMS consisted of 370 owners (75\%), 63 apprentices (13.8\%), and 58 employees or relatives $(11.8 \%)$. Their ages ranged from 15 to 80 years and all were literate. While some, 117 (23.8\%), had received training in healthcare, most had not. 104 PMS (21.2\%) had other jobs, with $63(14.7 \%)$ working in hospitals.

3.3. Report of Observations of Visits by Customers to PMS Shops. Most 1584 (61.9\%) of 2557 visits were made for medical reasons (the others were for purchase of nonmedical items or social visits). Of these medical visits, $1266(79.9 \%)$ were of customers who came to request for drugs without prescription and 117 of these requests were obviously for children. Just 19 (1.2\%) customers presented prescriptions for drugs for children. In most instances PMS simply sold the drugs requested. Only $29.5 \%$ gave customers instructions about doses, $2.6 \%$ about side effects, and $0.8 \%$ about precautions. Of 291 people who complained about illness, $86(29.6 \%)$ complained about children's illnesses, but 49 (57\%) did not bring them. Three customers were asked to go back and bring the children but 19 PMS sold caregivers drugs without asking any questions about the illness. Of 37 $(43 \%)$ children brought for treatment, 5 were asked to return later and 3 were sent into an inner room where the observer could not determine what happened. PMS were observed treating 29 children for fever, diarrhea, injuries, and skin lesions. Twenty-seven (93\%) PMS asked for clarification, 21 (75\%) examined the children, 7 (18.9\%) dressed or stitched wounds, and one gave a child an intravenous infusion. Most 27 (93\%) children received injections. Caregivers of children treated in shops were given advice about doses of drugs. Two children (with severe measles and sickle cell disease) were referred.
Thus at least 222 visits (117 drug requests, 19 prescriptions, and 86 consultations) involved children representing $14 \%$ of shop visits.

3.4. Management of Presumptive Malaria: Report of Interviews (Figure 1, Table 2). PMS were specifically asked about how they identified and managed children they thought had malaria.

3.4.1. Identification of Malaria. Only 18 (3.7\%) of the 491 PMS studied stated that they did not treat children for malaria because they did not see children or they referred them. The remaining 473 PMS used various combinations of methods to identify malaria. $226(47.8 \%)$ used past experience, 189 (39.6\%), physical examination, and 21(4.4\%) used laboratory tests. The main symptoms used to identify malaria were fever $318(66.1 \%)$, inability to eat $98(20.7 \%)$, weakness $70(14.2 \%)$, eye discoloration $29(6.1 \%)$ and vomiting 29 (6.1\%). Only one PMS mentioned convulsions.

3.4.2. Drug Therapy. There was no difference between types and doses of drugs used by PMS who had received professional health training and those who had not $(P>.5)$. PMS stated they used antimalarials, antipyretics, vitamins, antibiotics, and antitussives. 429 PMS who gave antimalarials $(90.7 \%)$ used chloroquine, $36(7.6 \%)$ used Sulfadoxinepyrimethamine (at the client's request), $6(1.3 \%)$ used Halofantrine, and $2(0.4 \%)$ used quinine. However $40 \%-$ $100 \%$ of stated doses of the different antimalarials; were incorrect. No PMS mentioned Artemisinin based-products.

3.4.3. Nondrug Therapies. Only 116 (19.4\%) PMS recommended that caregivers should use methods to reduce the child's temperature (exposure, tepid sponging, and cold baths). 23 PMS (4.9\%) recommended practices (hot baths, covering the child) which could lead to increase in temperature. Just $60(12.7 \%)$ PMS mentioned use of mosquito nets (mainly more often by PMS who were health professionals; $P=.03)$.

3.4.4. Referral. Forty (57\%) of 70 PMS who had recently referred children had treated them for three or more days. Reasons for referral were inability to handle the illness, 27 (38.6\%), lack of improvement, 25(35.7\%), severe illness, 6 $(8.6 \%)$, or laboratory tests, $2(2.9 \%)$. The rest gave no reason.

3.5. Drug Inventory. In the week preceding the survey, PMS estimated that they had sold 8,430 doses of paracetamol, 5,413 doses of chloroquine (mainly syrups, also tablets, and injections), 102 doses of sulfadoxine-pyrimethamine, and 3 doses of quinine. Chloroquine and paracetamol were popular because they were effective, well known to customers, and cheap (less than two US dollars).

\section{Discussion}

Improving access to prompt, effective, and appropriate treatment is a key element of the Global Malaria Programme 


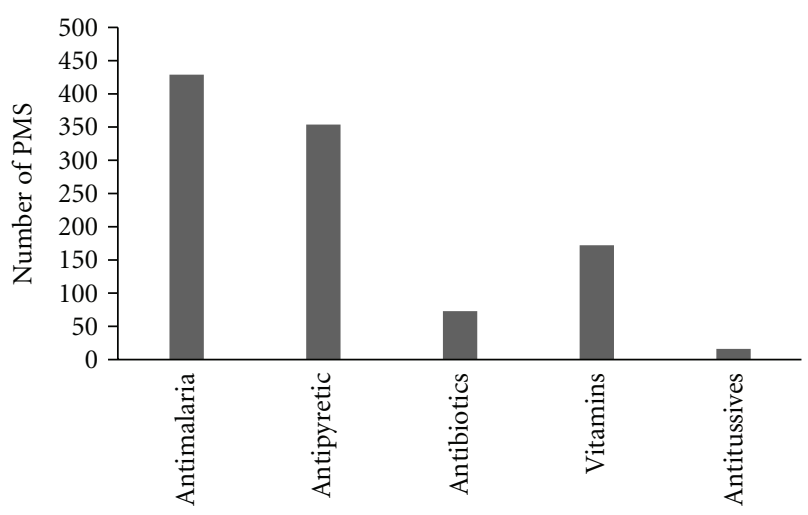

PMS: Patent medicine sellers

Figure 1: Drugs used by Patent Medicine Sellers in treatment of Malaria.

Strategy $[2,3]$. The study shows that PMS have the potential to improve access, but they need skills and knowledge to manage malaria. They acted mainly as facilitators for home care (as the great number of requests by their customers for drugs without prescription indicates a community that was actively involved in self-care). PMS also treated sick children brought to the shop. However they had deficiencies in knowledge and practice. Many did not know the correct dose of antimalarials children should receive. Most failed to give customers advice about drug doses or administration. Some did not ask questions about illness for which they were consulted, and many used injections to treat children. Few promoted non-drug methods of treatment or use of bednets.

Other studies reveal that PMS frequently give no or inappropriate advice about drugs $[10,14,15,17]$. This highlights one weakness of Home Management of Malaria (HMM) which aims to ensure prompt and effective care of sick children by educating mothers and distributors of antimalarials in the community $[33,34]$. Many mothers in developing countries get drugs from PMS or drug hawkersusually without prescription [10, 17, 19]. Unfortunately, because the person selling the drug or the one administering it does not know the correct dose, children are given inappropriate doses of antimalarials leading to development of severe disease and death $[10,17,35,36]$. The study shows that interventions involving PMS should focus on training them to determine the correct dose of antimalarials and encourage them to give customers advice about administration. Children's doses vary and are usually calculated using weight, surface area, or age. As most children were not taken to the shops, use of weight or surface area is clearly impractical but using age is feasible. In some countries antimalarials are prepackaged or colour coded according to age, and these have been used with great success [37, 38]. In many areas, though, such drugs are not available or affordable, and so other simple methods of determining doses are needed. Age could be used to calculate dose as a percentage of the normal adult dose but PMS would need training on how to do this. Pictorial guides in the shop and inserts in drugs packets could help but inserts increase cost of drugs.

PMS also need to know about changes in malaria treatment. It is striking that none of them mentioned Artemisinin-Combination Therapies (ACTs). This might have been because, at the time of the study, first-line treatment consisted of chloroquine which was cheap and effective. Due to increasing drug resistance, the government changed its malaria treatment policy and adopted ACTs as first-line drugs in 2005, but many PMS were unaware of this $[39,40]$. At present, though, ACTs cannot legally be sold by PMS because they are classified as prescription drugs [39]. Changing their status to over-the-counter requires legislation, a process that is currently underway as the Federal Ministry of Health proposes to use ACT at community level to improve HMM [39]. Use of ACTs might also help reduce the high rate of injections given to children treated in shops and so reduce risk of infection, nerve paralysis, and danger to the community caused by improper disposal of needles.

It is of note that some PMS dispensed drugs without asking questions (in essence relying on the caregivers' diagnosis). The importance of PMS asking questions about illness, for which they are consulted needs to be stressed because it helps identify those children who need urgent referral to health facilities For example, those with danger signs like vomiting, refusal, or inability to feed [41].

The study was limited in that some PMS were cautious about letting researchers see how they treated children because the Government Task Force was threatening to close down shops for illegal activities. Thus it is likely that many more children were treated than was recorded. Also some PMS may have adopted different behaviours to their normal ones because they were being observed but the most probable result of this would be that more,not less, PMS than normal would give customers advice about drugs. Determining the effect medical personnel who were not PMS had on patient management was outside the scope of the study, so was determining the accuracy of PMS diagnosis of illnesses, the doses they actually gave, or the extent their advice or lack of it had on the health of their customers.

The study shows that PMS need training in order to improve their role in malaria control in the community. However generally governments of developing countries have been reluctant to train informal health providers and instead have concentrated on training health workers in the public sector $[10,17]$. Both knowledge and practices can be improved through training. In Nigeria, training PMS on a range of common conditions in adults led to an improvement in their knowledge though the impact on their practice was not evaluated [23]. In Kenya, training resulted in an increase in the proportion of antimalarial drug users who received an adequate dose [42]. The HMM strategy advocates training community-based service providers to dispense antimalarials and educate mothers about the correct dose to give [34]. However surprisingly few programs have considered using PMS as the community-based service providers. This might be because of distrust and perceived possibility of PMS to maximize profit [40]. But Ajayi et al. carried out a malaria intervention program in Southwest Nigeria using 
TABLE 2: Appropriateness of doses of antimalarials used by patent medicine sellers in treatment of malaria.

\begin{tabular}{|c|c|c|c|c|}
\hline \multirow{2}{*}{ Drug } & \multicolumn{3}{|c|}{$\%$ PMS who used inappropriate doses } & \multirow{2}{*}{$\begin{array}{l}\text { \% PMS who used } \\
\text { appropriate doses } \\
\% \text { Total correct }\end{array}$} \\
\hline & $\%$ Under-dose & $\%$ Over-dose & $\%$ Total incorrect & \\
\hline Chloroquine & 23.2 & 50.6 & 73.8 & 26.3 \\
\hline Sulfadoxine-pyrimethamine & 19.2 & 34.6 & 53.8 & 46.2 \\
\hline Halofantrine & 40.0 & 0.0 & 40.0 & 60.0 \\
\hline Quinine & 100.0 & 0.0 & 100.0 & 0.0 \\
\hline
\end{tabular}

PMS to distribute drugs to mothers, and they reported that most caregivers perceived PMS as accessible and efficient at drug distribution [40]. They were quick to add, though that, for good distribution to be maintained, PMS would need to receive incentives in the form of commission for the antimalarials they sold or distributed. Training however arouses fears that this would be interpreted by the public as official recognition of PMS as health providers. Definitely continued supervision is needed to sustain changes and ensure a minimum standard of care. Further improvement in availability, and quality of public services by the government is necessary as PMS cannot take the place of public facilities.

However as people are likely to continue to patronize PMS for a long time, it is recommended that training and retraining should be made a prerequisite for registering and reregistering shops. The effect training has on doses and drugs dispensed in communities needs to be monitored at regular intervals. Further, more research is needed to determine what other sorts of interventions involving PMS could assist in prevention and management of childhood malaria. The feasibility or otherwise of officially recognizing PMS roles in healthcare needs further consideration and discussion.

\section{Conclusion}

PMS have the potential to improve malaria control in the community through improving access of caregivers to effective and appropriate treatment. Interventions involving them should focus on certain key issues-training them on how to determine the correct dose of appropriate antimalarials, give advice about drug administration, and use insecticidetreated nets. They should also be encouraged to use oral medications instead of injections and ask questions about illness for which they are consulted. Training, supervision, and research in various aspects are all needed. Possible official recognition of their roles in healthcare needs further consideration. If we ignore PMS, we do so at our peril (or more realisticallyat that of our children).

\section{Acknowledgments}

The study was funded by the Applied Research for Childhood Diseases (ARCH). The authors thank the Kaduna State Chairman, the members of the National Association of Patent and Propriety Medicine Dealers (NAPPMED), and the Patent Medicine Sellers who participated in the study.

\section{References}

[1] United Nations, "The millennium development goals report 2008," British Medical Journal, vol. 337, 2008.

[2] J. G. Breman, M. S. Alilio, and A. Mills, "Conquering the intolerable burden of malaria: what's new, what's needed: a summary," American Journal of Tropical Medicine and Hygiene, vol. 71, no. 2, supplement, pp. 1-15, 2004.

[3] The United Nations Children's Fund, Malaria and Children. Progress in Intervention Coverage, UNICEF, 2007.

[4] B. M. Greenwood, A. K. Bradley, A. M. Greenwood et al., "Mortality and morbidity from malaria among children in a rural area of The Gambia, West Africa," Transactions of the Royal Society of Tropical Medicine and Hygiene, vol. 81, no. 3, pp. 478-486, 1987.

[5] World Health Organization, "Home management of malaria," http://www.malaria.who.int/homemanagement.

[6] E. Enato and A. Okhamafe, "A survey of anti-malarial activity during pregnancy, and children's malaria care-seeking behaviour in two Nigerian rural communities," Scandinavian Journal of Infectious Diseases, vol. 38, no. 6-7, pp. 474-478, 2006.

[7] L. A. Salako, W. R. Brieger, B. M. Afolabi et al., "Treatment of childhood fevers and other illnesses in three rural Nigerian communities," Journal of Tropical Pediatrics, vol. 47, no. 4, pp. 230-238, 2001.

[8] R. W. Snow, N. Peshu, D. Forster, H. Mwenesi, and K. Marsh, "The role of shops in the treatment and prevention of childhood malaria on the coast of Kenya," Transactions of the Royal Society of Tropical Medicine and Hygiene, vol. 86, no. 3, pp. 237-239, 1992.

[9] W. Were, "Bringing malaria management closer to the home," Roll Back Malaria Department, World Health Organization, Geneva, Switzerland, WHO Mera iii, May 2004.

[10] C. Goodman, W. Brieger, A. Unwin, A. Mills, S. Meek, and G. Greer, "Medicine sellers and malaria treatment in subSaharan Africa: what do they do and how can their practice be improved?" The American Journal of Tropical Medicine and Hygiene, vol. 77, no. 6, supplement, pp. 203-218, 2007.

[11] S. van der Geest, "Self-care and the informal sale of drugs in South Cameroon," Social Science and Medicine, vol. 25, no. 3, pp. 293-305, 1987.

[12] O. Onwujekwe, "Inequities in healthcare seeking in the treatment of communicable endemic diseases in Southeast Nigeria," Social Science and Medicine, vol. 61, no. 2, pp. 455463, 2005.

[13] "Strategies for Enhancing Access to Medicines (SEAM)," in Proceedings of the Targeting Improved Access to Essential Medicine Conference, Accra, Ghana, June 2005, http://www .msh.org/seam/conference2005/. 
[14] R. Brugha and A. Zwi, "Improving the quality of private sector delivery of public health services: challenges and strategies," Health Policy and Planning, vol. 13, no. 2, pp. 107-120, 1998.

[15] A. L. Raynal, "Use of over-the-counter medications in rural Matabeleland, Zimbabwe: the case for upgrading the dispensing skills of rural storekeepers," Central African Journal of Medicine, vol. 31, no. 5, pp. 92-97, 1985.

[16] F. O. Oshiname and W. R. Brieger, "Primary care training for patent medicine vendors in rural Nigeria," Social Science and Medicine, vol. 35, no. 12, pp. 1477-1484, 1992.

[17] Y. Tawfik, R. Northrup, and S. Prysor-Jone, "Utilizing the potential of formal and informal private practitioners in child survival: situation analysis and summary of promising interventions," Tech. Rep., Support for Analysis and Research in Africa (SARA) Project, Academy for Educational Development, Washington, DC, USA, 2002, http://pdf.usaid.gov/pdf_docs/PNACP202.pdf.

[18] A. Mills, R. Brugha, K. Hanson, and B. McPake, "What can be done about the private health sector in low-income countries?" Bulletin of the World Health Organization, vol. 80, no. 4, pp. 325-330, 2002.

[19] T. A. Okeke, B. S. C. Uzochukwu, and H. U. Okafor, "An indepth study of patent medicine sellers' perspectives on malaria in a rural Nigerian community," Malaria Journal, vol. 5, article 97, 2006.

[20] A. Ojuawo and O. T. Oyaniyi, "Treatment of diarrhoea by proprietary-medicine vendors," Nigerian Journal of Paediatrics, vol. 20, no. 2, pp. 41-44, 1993.

[21] S. E. D. Nsimba, "Assessing the performance, practices and roles of drug sellers/dispensers and mothers'/guardians' behaviour for common childhood conditions in Kibaha district, Tanzania," Tropical Doctor, vol. 37, no. 4, pp. 197-201, 2007.

[22] U. A. Igun, "Reported and actual prescription of oral rehydration therapy for childhood diarrhoeas by retail pharmacists in Nigeria," Social Science and Medicine, vol. 39, no. 6, pp. 797806, 1994.

[23] W. R. Brieger, P. E. Osamor, K. K. Salami, O. Oladepo, and S. A. Otusanya, "Interactions between patent medicine vendors and customers in urban and rural Nigeria," Health Policy and Planning, vol. 19, no. 3, pp. 177-182, 2004.

[24] J. Wright and J. Walley, "Health needs assessment. Assessing health needs in developing countries," British Medical Journal, vol. 316, no. 7147, pp. 1819-1823, 1998.

[25] World Health Organization, "World Health Statistics, 2007," World Health Organization, Geneva, Switzerland, 2007.

[26] Federal Ministry of Health, Malaria Desk Situation Analysis, Abuja National Malaria Control Program, Federal Ministry of Health, Abuja, Nigeria, 2000.

[27] National Population Commission (Nigeria), Nigeria Demographic and Health Survey 1999, National Population Commission and ORC/Macro, Calverton, Md, USA, 2000.

[28] TripAtlas.com, Kaduna, www.tripatlas.com/Kaduna.

[29] M. U. Adikwu, "Sales practices of patent medicine sellers in Nigeria," Health Policy and Planning, vol. 11, no. 2, pp. 202 205, 1996.

[30] J. E. Ehiri, A. E. Oyo-Ita, E. C. Anyanwu, M. M. Meremikwu, and M. B. Ikpeme, "Quality of child health services in primary health care facilities in south-east Nigeria," Child: Care, Health and Development, vol. 31, no. 2, pp. 181-191, 2005.

[31] J. R. M. Armstrong Schellenberg, T. Adam, H. Mshinda et al., "Effectiveness and cost of facility-based integrated management of childhood illness (IMCI) in Tanzania," The Lancet, vol. 364, no. 9445, pp. 1583-1594, 2004.

[32] Federal Ministry of Health, "National Antimalarial Treatment Policy," Federal Ministry of Health, Nigeria, 2005.

[33] World Health Organization, The African Summit on Roll Back Malaria, World Health Organization, Abuja, Nigeria, 2000.

[34] World Health Organization, The Roll Back Malaria Strategy for Improving Access to Treatment through Home Management, World Health Organization, Geneva, Switzerland, 2005.

[35] N. Nshakira, M. Kristensen, F. Ssali, and S. Reynolds Whyte, "Appropriate treatment of malaria? Use of antimalarial drugs for children's fevers in district medical units, drug shops and homes in eastern Uganda," Tropical Medicine and International Health, vol. 7, no. 4, pp. 309-316, 2002.

[36] O. A. Dada and F. O. Omokhodion, "Home management of malaria bymothers of children under-five in Abeokuta, Southwest Nigeria," Tropical Doctor, vol. 37, no. 4, pp. 217219, 2007.

[37] W. R. Brieger, L. A. Salako, R. E. Umeh, P. U. Agomo, B. M. Afolabi, and A. K. Adeneye, "Promoting prepackaged drugs for prompt and appropriate treatment of febrile illnesses in rural Nigerian communities," International Quart. Community Health Education, vol. 21, pp. 19-40, 2002.

[38] S. B. Sirima, A. Konaté, A. B. Tiono, N. Convelbo, S. Cousens, and F. Pagnoni, "Early treatment of childhood fevers with pre-packaged antimalarial drugs in the home reduces severe malaria morbidity in Burkina Faso," Tropical Medicine and International Health, vol. 8, no. 2, pp. 133-139, 2003.

[39] Federal Ministry of Health, National Strategies and guidelines for Home and Community Management of Malaria, Federal Ministry of Health, Abuja, Nigeria, 2005.

[40] I. O. Ajayi, C. O. Falade, B. O. Olley et al., "A qualitative study of the feasibility and community perception on the effectiveness of artemether-lumefantrine use in the context of home management of malaria in south-west Nigeria," $B M C$ Health Services Research, vol. 8, article 119, 2008.

[41] WHO and UNICEF, IMCI Chart Booklet, WHO, Geneva, Switzerland, 2008, http://www.who.int/child\%5C_adolescent \%5C_health/documents/IMCI\%5C_chartbooklet/en/index .html\%20-\%2016k.

[42] V. M. Marsh, W. M. Mutemi, A. Willetts et al., "Improving malaria home treatment by training drug retailers in rural Kenya," Tropical Medicine and International Health, vol. 9, no. 4, pp. 451-460, 2004. 


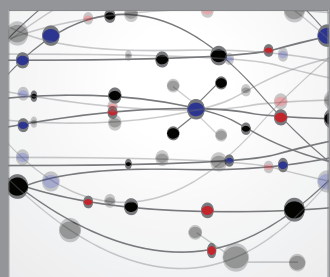

The Scientific World Journal
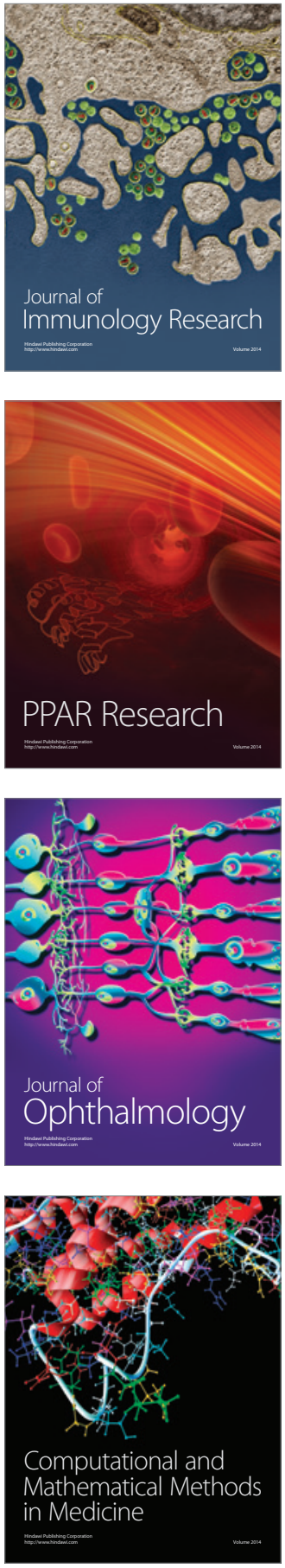

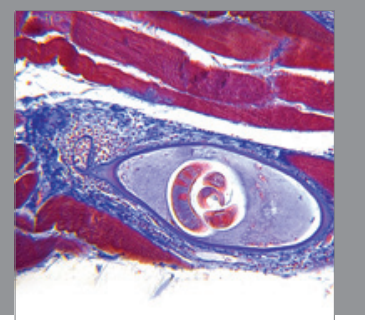

Gastroenterology

Research and Practice
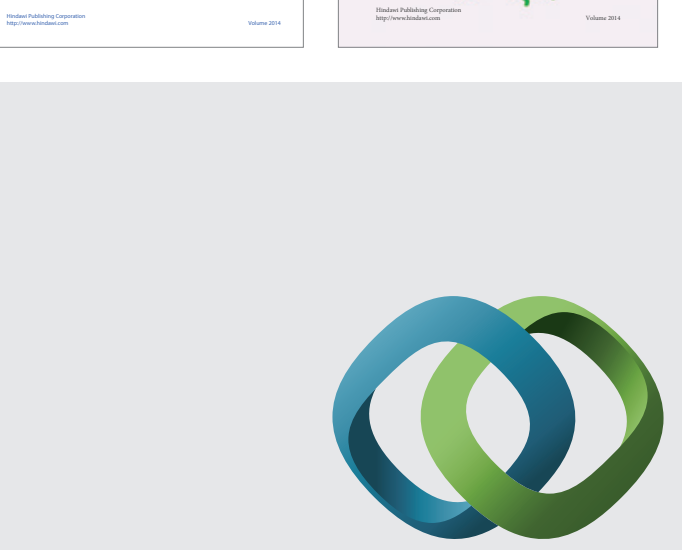

\section{Hindawi}

Submit your manuscripts at

http://www.hindawi.com
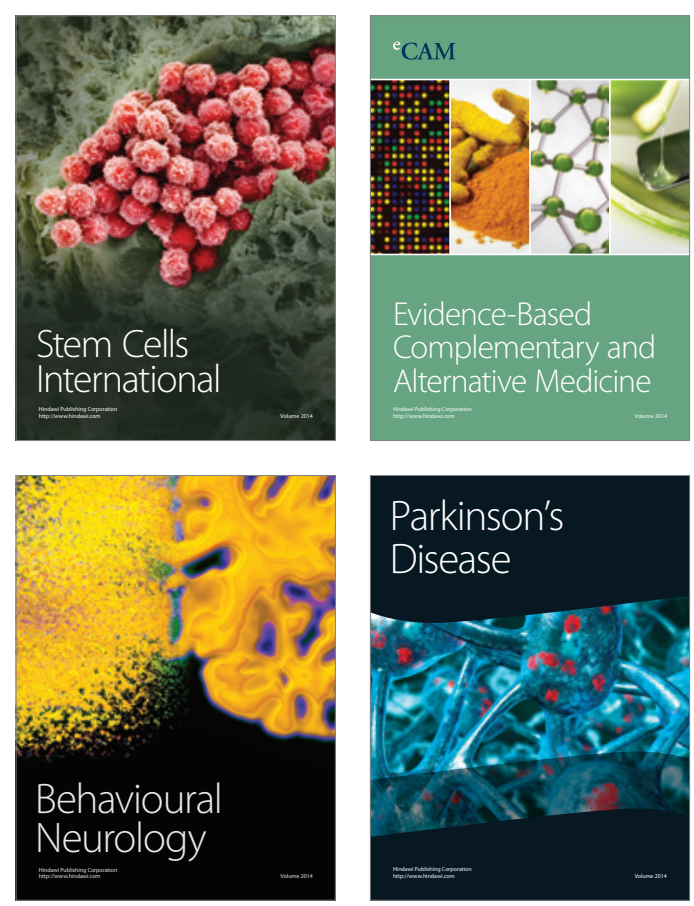

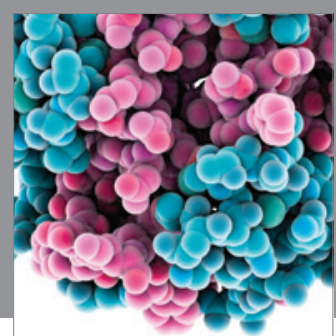

Journal of
Diabetes Research

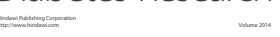

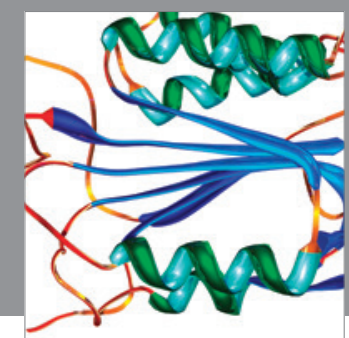

Disease Markers
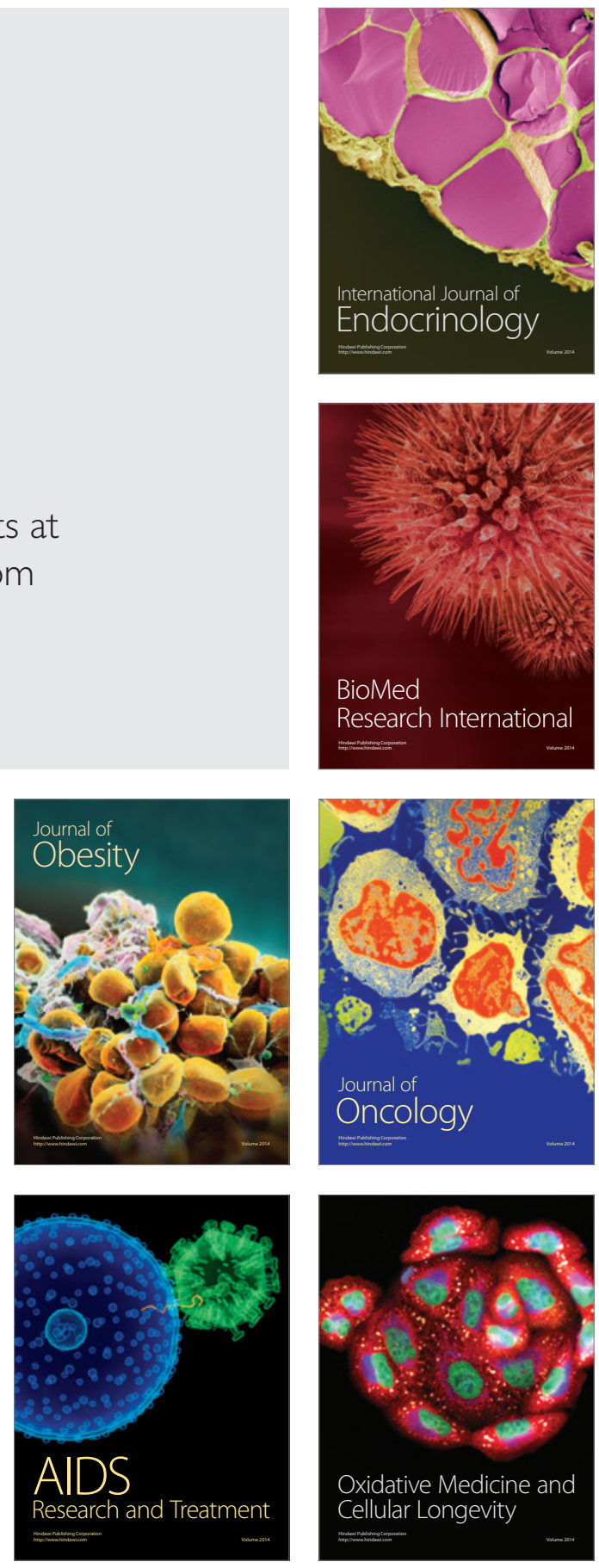